\title{
Mountain Bicycle Cycling Comfort on Different Road Surfaces
}

\author{
Soffarina Mohd Soffie Suppiah \\ Faculty of Mechanical Engineering, Universiti Malaysia Pahang, Malaysia \\ Email: soffarina@gmail.com
}

\begin{abstract}
Mountain bicycle is one of the types of bicycles, and it is made for off-road cycling. The main objective of the research is to focus on the surface of the road and weight to obtain and measure the vibration produce on the mountain bicycle. In order to investigate the vibrations, an accelerometer is placed under the saddle of the bicycle in order to get an accurate reading for different types of surfaces and the vibration of the weight. The cyclist had to cycle for $400 \mathrm{~m}$ in the average of 5.1 to 6.1 revolutions per minute on four different surfaces, and four different weight were investigated. The results show that the highest acceleration produced is which refers to mean value is the acceleration of loose gravel which is 0.46190 . There is an insignificant value in the weight of the driver weighing $60 \mathrm{~kg}$ if replaced with $70 \mathrm{~kg}, 80 \mathrm{~kg}$ if the bike is running on four different kinds of roads.
\end{abstract}

Keywords Mountain bicycle, vibration, road surface, driver load Paper type Research paper

\section{INTRODUCTION}

Bicycle is known as cycle or bike, is manually done by a human being or human-powered, pedal-driven, is one of the environmentally-friendly vehicles. The word bicycle first appears in an English newspaper in the Daily News in 1868, describe bicycles and tricycles on the Champs Elysées and Bois de Boulogne [1]. They provide transportation to many areas in the form of recreation, general fitness, military, courier services and bicycle racing. The first chain-driven model was developed around 1885 on the basic shape of the typical upright or safety bicycle [2-5]. This type of bicycle became very popular in the late 1880s as an alternative to the penny-farthing and now it is the most common type of bicycle. They are known as safety bicycles because they were noted for, marketed as safer (safety factor) than the high wheeler they were replacing. [6] Nowadays, the term safety bicycle is rarely used and considered obsolete even though the modern bicycle uses a similar design; therefore, every bicycle created in this modern era is considered safe [7].

Mountain bicycle (MTB) is one of the types of bicycles, and it is made for off-road cycling. It has the same function and features with other bikes but MTB has a feature designed to increase its performance in rough terrain and endurance. The history of MTB was started by the riders where they were attracted by the thrill of riding down the fire roads or single- track trails. It all started in the wilderness area around Mount Tamalpais in Mann County, California. The one who experimented with equipment and frames to make his machine suitable for the rough trail was Gary Fisher. Gary Fisher used the Schwinn Excelsior frame because it provides better pedal-to-ground clearance and used drum brakes with motorcycle brake levers. After it, the riders could ride up to the mountain aster the derailleurs were incorporated. In 1979, MountainBikes company became the generic name of this type of bicycle founded by Gary Fisher and Charlie Kelly. The original MTB only include gear and recently, suspension forks were added where the idea came from motorcycle design.

This bicycle typically rode on an unpaved, irregular and rough surface. Typically, it will be ridden on the fire roads, logging roads, mountain trails, single tracks, and other unpaved environments. Besides, types of terrain that are suitable for the bicycle are ruts, washouts, rocks, loose sand, loose gravel, steep grades (both inclines and declines) and root. Therefore, a mountain bicycle has the highest vibration on the pads (seat), frame and brakes. The weight of the cyclist plays an essential role in the bike. Vibration can make a person uneasy and not comfortable during riding, and cyclist usually rides their bikes four hours in a single trip. Comfort is essential for cyclists as more energetic vibration will lead to a less comfortable ride [8-9]. Vibration comes from unwanted noise and friction of the object's effect from the weight of a person, road surface, frame structure and the type of tire (thread pattern). The objective of the research to investigate the road transmitted vibration to the mountain bicycle seat.

\section{MOUNTAIN BICYCLE}

MTB or All-Terrain Bicycle (ATB) used rigid fork blade rather than suspension system, conventionally change at the front suspension system. The first advantage of using the rigid fork blades that the ability of the bicycle to be ridden off-road a less vibration occurs. Therefore, the ride becomes ease and comfortable. Comfort also and be decrease with higher velocities [10]. Jerry stated that the suspension system act as an absorber shock where it will absorb the bumps of the roads and trail and a small amount of natural flexibility in the frame because the rigid 
frame of the bicycles relies on special tires, a wide cross-section. A rigid frame with a rigid fork blade is more suitable for a rider who likes to pedal hard for maximum power and efficiency, and human energy output is transmitted directly to the rotation of the rear wheel allowing vibration empowered. The investigation will be carried out on the MTB bicycle on different roads and different weights. Typically it will be ridden on the fire roads, logging roads, mountain trails, single tracks and other unpaved environments. Besides, types of terrain that are suitable for the bicycle are ruts, washouts, rocks, loose sand, loose gravel, steep grades (both inclines and declines), concrete slabs, asphalt surface, cobblestone root and self-binding gravel. Therefore, focus on four types of the road such as loose gravel (sand), asphalt surface, concrete slabs and bicycle tracks as shown in Figures 1-2.

The bicycle has 105 parts included small parts of the bicycle as shown in Figure 3. For a better understanding of the experiment, first by knowing details on the bicycle will make the project more precise. Explaining related parts of the bicycle with the attachment of accelerometer and vibration will give a great understanding of this project.
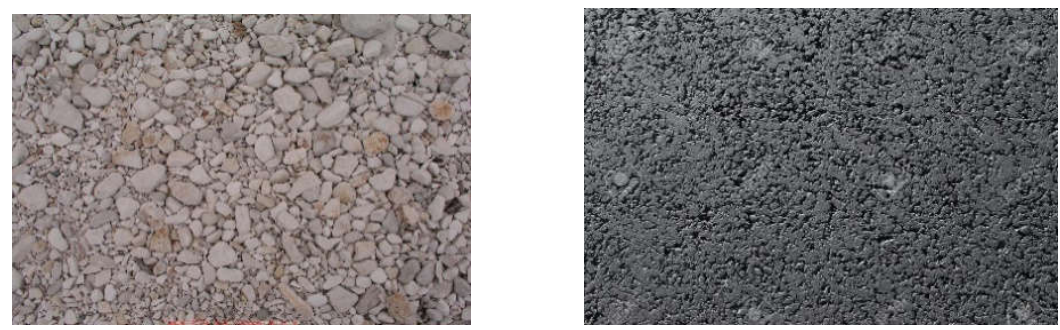

Fig. 1.Loose gravel (sand) (left) and asphalt surface (right)
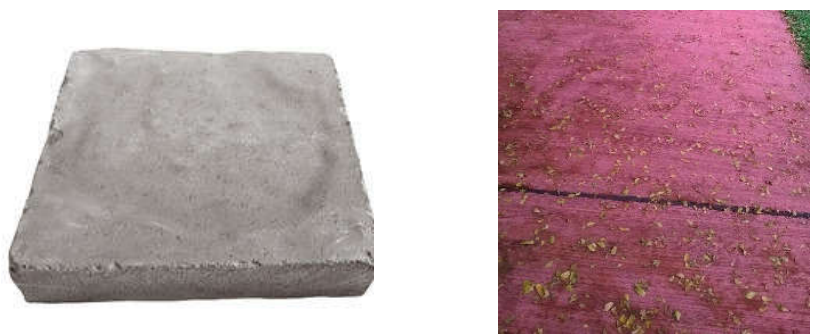

Fig. 2. Concrete slabs (left) and bicycle track (right)

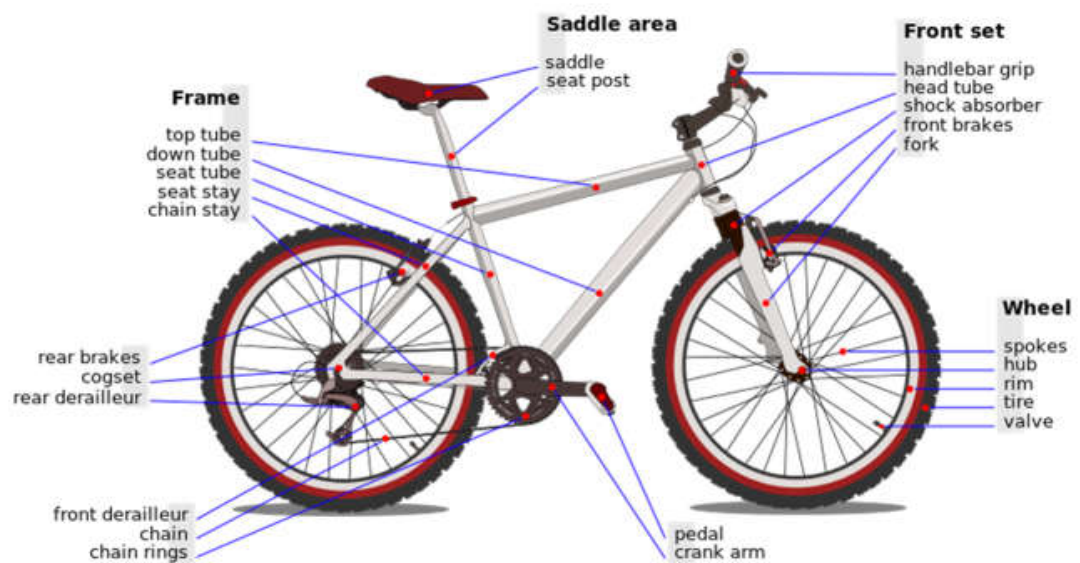

Fig. 3. Bicycle parts

The quality of the ride is often used terms of quantifying the quality of a bicycle due to its frame geometry, especially the damping and stiffness of the bicycle [1]. The effect of transmitted road vibrations in cycling was measure by Hasting et al. 2004, where they specially fabricated the clamping system and attached the accelerometer to standardized the test on the trade mill [2]. In every cycle, cyclist priority need is comfort. Comfortable cycling is required smooth rolling at the lowest as the possible energy input. There is much pain due to cyclings such as hip pain, knee pain, foot pain, ankle pain, back pain, neck pain and hand pain. The most complaint of pain is the knee pain due to the nature bicycle itself, the man-machine interaction. The effect of knee pain is caused by force applied on the bike takes reaction back to the leg. The best way is to increase the height of the seat by measuring by bending the legs 900. If the knee pain still occurs, this is due to friction and vibration of the bicycle that makes the cyclist be 
uncomfortable. Christin Hölzel et al. use a method whereby the rolling resistance was quantified using one degree of freedom pendulum, transversal rotation for the tire of the bicycle [1]. An accelerometer will be applied under the seat of the racing bicycle in order to obtain the vibration. Lower rolling resistance stands for lower energy input which is to increase comfort. There are several methods had been used to determine $\mathrm{Rr}$ in other studies [1]. Bicycle rolls down a constant grade slope was a method used by Vann der Plass. [3] The coefficient of rolling resistance $(\mathrm{Cr})$ can be calculated out from the results by the predominant force during the test being assume and require the movement is measured. [3] To obtain $\mathrm{Cr}$, the coefficient of rolling resistance is not suitable because it requires smooth surfaces that are not in the analysis of these studies. Therefore, Wang et.al in 2004 commented on the other three methods which are large-diameter rotating drums, a tricycle configuration and a rotating, oscillating weight [4]. Four different surfaces will be investigated such as loose gravel (sand), asphalt surface, concrete slabs and bicycle tracks.

\section{METHODOLOGY}

The experiment is based on the vibration of the mountain bicycle on the various road surfaces and weight. By including all the parameters requires the use of National Instrument Measurement \& Automation Explorer software. Selecting the sensor on the acceleration in order to observe the movement of the vibration under saddle. The piezoelectric accelerometer is placed under the saddle of the bicycle to get an accurate and precise measurement due to the weight-related of the cyclist, as shown in Figure 4. Also, a speedometer attached in the steer. DAQ act as a transducer that converts a phenomenon take by equipment or device to a detectable, measurable electric signal. DAQ are connected with DASY Lab where the data can obtain accurately and also can be analyzed, measure, observe and control.

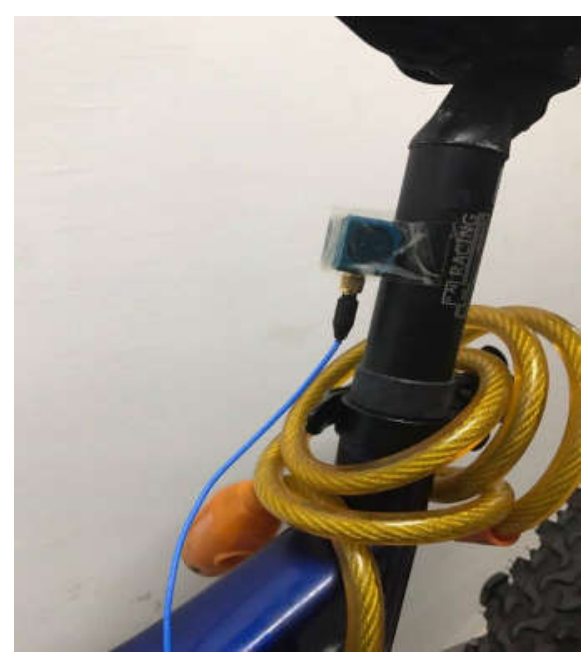

(a)

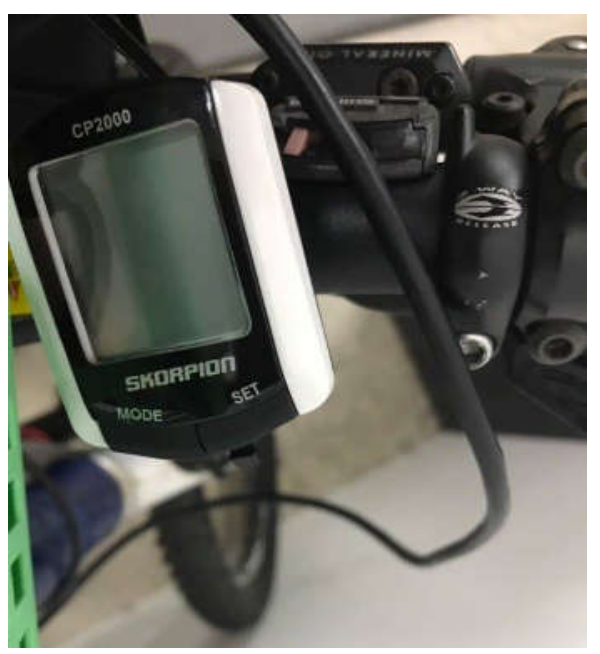

(b)

Fig. 4.a) A piezoelectric accelerometer under the saddle b) A speedometer attached in the steer

The cyclist was cycling for $400 \mathrm{~m}$ length in the speed range between 5.1 to $6.1 \mathrm{rpm}$ (revolution per minute). The cyclist needs to maintain its speed by using a speedometer as shown above for the entire four different surfaces, such as asphalt surface, bicycle track, loose gravel, and concrete slab.

\section{RESULTS AND DISCUSSION}

Based on the accelerometer reading, that data was obtained. The various method are used to investigate the vibration of the bicycle. The reason for placing the accelerometer under the saddle instead at the hub is due to a co-related factor of weight of the cyclist. One of the effects to position the accelerometer under the saddle is because the excitation will have oscillated from the road surface to the weight of the cyclist which has a tremendous significant effect on the bicycle. The experiment is carried out on a moving bicycle throughout on road surfaces with a constant length of $400 \mathrm{~m}$ and constant revolution per minute (rpm) of 5.1 to $6.1 \mathrm{rpm}$. The graph of the mean value surface against the road surface can be seen in Figure 5. The first bar represents asphalt surface, 0.00959, and the second bar is loose gravel, 0.461896563 while the third bar is concrete slab, 0.01611 and lastly, it represents the bicycle track, 0.051308125 . As shown below that the highest effect of vibration on the bicycle itself is loose gravel with a mean value of 0.46190 and has the highest significant effect on the oscillation. Using the Tukey test it shows that there is a significant value between each group and there are vibration occurred in each group. 


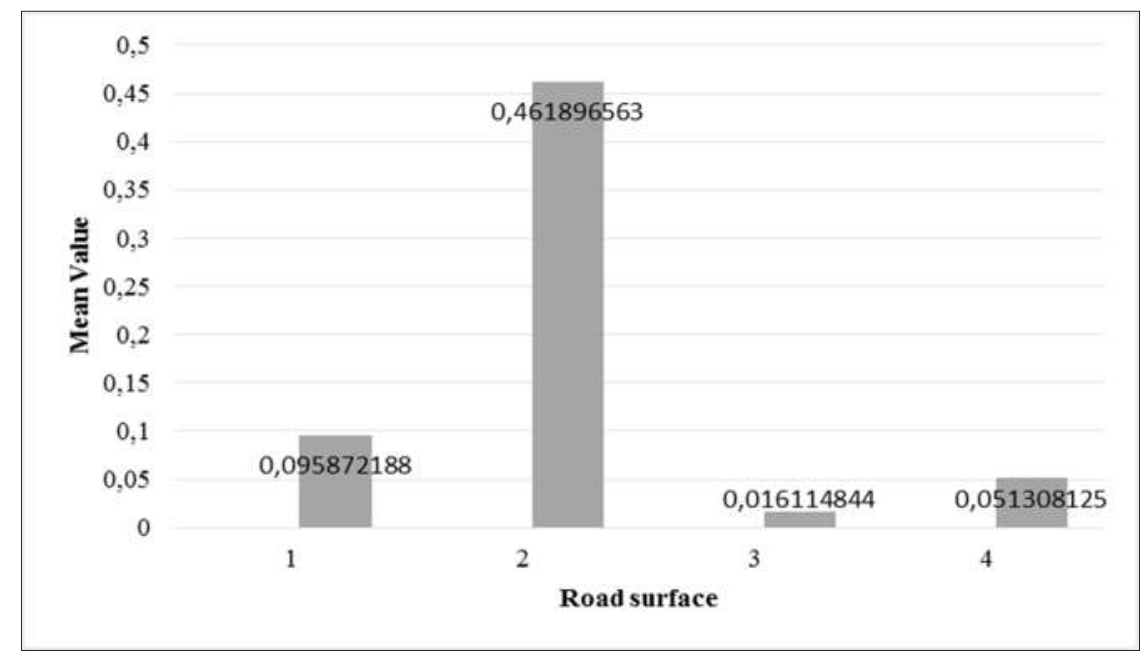

Fig. 5. The graph of mean value surface against the road surface (road surface $1=$ asphalt surface, $2=$ bicycle track, 3 = loose gravel and $4=$ concrete slabs)

By calculating more detail by using Tukey HSD test in Vassar Stats calculation, the weight of the driver or load was changed if the bike is running on four different kinds of roads. There is a non-significant value on weight 60 $\mathrm{kg}$ group with $70 \mathrm{~kg}, 80 \mathrm{~kg}$. Also, the weight $70 \mathrm{~kg}$ does not have a significant effect on the weight of $80 \mathrm{~kg}$ as shown in Figure 6. However, the weight of $60 \mathrm{~kg}, 70 \mathrm{~kg}$, and $80 \mathrm{~kg}$ have a significant effect on $90 \mathrm{~kg}$. Therefore, the comparison can be shown in Figure 6.

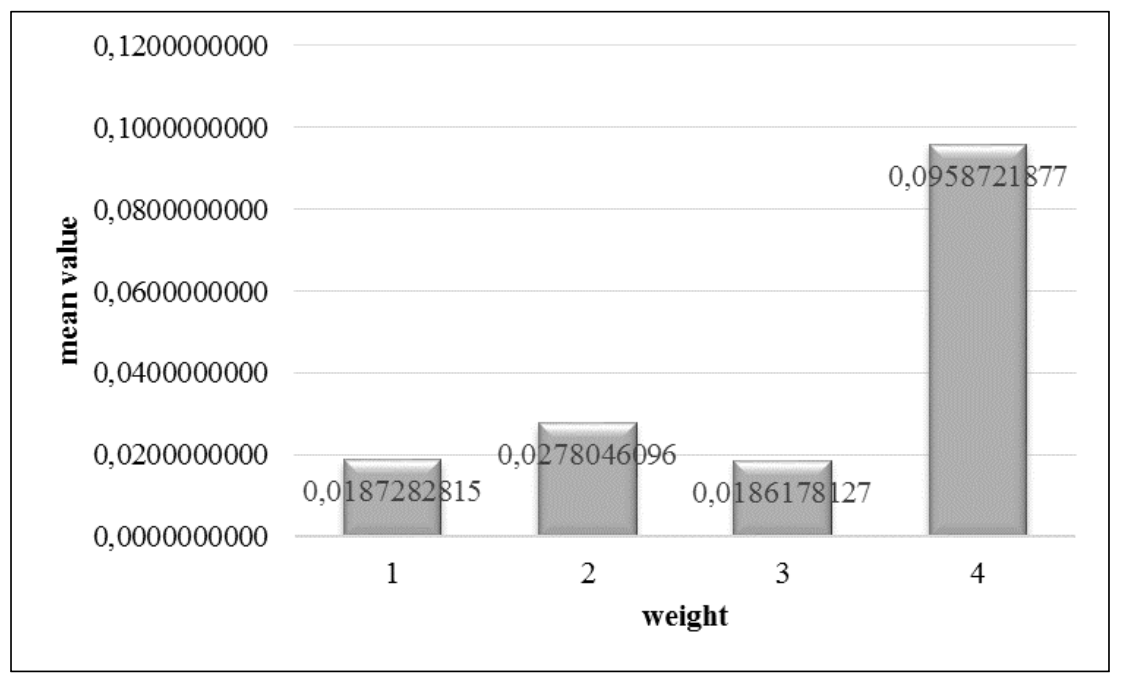

Fig. 6 . The Graph of mean value against weights (weights $1=60 \mathrm{~kg}, 2=70 \mathrm{~kg}, 3=80 \mathrm{~kg}$ and $4=90 \mathrm{~kg}$ )

\section{CONCLUSION}

Based on the experiment results, it can be seen that the vibration of the bicycle increases if the road surface is more stringent, and the vibration of the bicycle increase if the weight of the driver is increasing. The highest acceleration produced is which refers to mean value is the acceleration of loose gravel which is 0.46190 . There would be a non-significant value on weight if it was changed $60 \mathrm{~kg}$ with $70 \mathrm{~kg}, 80 \mathrm{~kg}$.

\section{REFERENCES}

[1] F. Giubilatoa, N. Petrone, "A method for evaluating the vibrational response of racing bicycles wheels under road roughness excitation," Procedia Engineering, 34, 409 - 414, 2012.

[2] M. Oliemana, R. Marin-Perianua, M. Marin-Perianub, "Measurement of dynamic comfort in cycling using wireless acceleration sensors," Procedia Engineering, 34, 568-573, 2012.

[3] C. Hölzel, F. Höchtla, V. Senner, "Cycling comfort on different road surfaces," Procedia Engineering, 34, 479-484, 2012.

[4] V. der Plaas, R. Rolling, "Resistance of bicycle tires," Bike Tech, 2, 8-12, 1983. 
[5] P. W. Macdermid, M. C. Miller, F. M. Macdermid, P. W. Fink, "Tyre Volume and Pressure Effects on Impact Attenuation during Mountain Bike Riding," Shock and Vibration, 2015.

[6] A. Z. Hastings, K. B. Blair, F. K. Culligan, D. M.Pober, "Measuring the effect of transmitted road vibration on cycling performance," In: Hubbard M, Mehta RD, Pallis JM, editors. The Engineering of Sport, 5, Vol. 22004.

[7] M. Levy, "Kinetic and Vibration Analysis of Off-Road Bicycle Suspension Systems," (2000).

[8] E. Wang, V. Macedo, J. A. Reid, "Method for quantifying rolling resistance of bicycle tires," In: M. Hubbard, R. D. Mehta, J. M. Pallis, editors. International Sports Engineering Association, Vol. 2, p. 132-138, 2004.

[9] K. Y. Billah, R. H. Scanlan, R.H., "Resonance, Tacoma Narrows Bridge Failure, and Undergraduate Physics Textbooks," American Journal of Physics Teachers, Vol.59, No.2. pp.118-124, 1991. 
Soffarina Mohd Soffie Suppiah 